\title{
ADAPTAÇÕES E ESTRANHAMENTOS EM A MASSAI BRANCA
}

\author{
CARMO, Erinaldo Ferreira ${ }^{1}$ \\ OLIVEIRA, Érica Patrícia Barbosa² \\ SILVA, Fernanda Maria ${ }^{3}$
}

\begin{abstract}
RESUMO:
As diferenças culturais, as questões de gênero e o conhecimento do povo Samburu, em suas relações com o espaço geográfico e com o seu meio social, são temáticas abordadas neste artigo construído a partir da interação entre estudantes e professores de diferentes disciplinas do Colégio de Aplicação da Universidade Federal de Pernambuco. O eixo norteador é o filme $A$ Massai Branca, baseado em uma história real que mostra a relação de contrastes entre uma mulher suíça e um guerreiro Samburu, personagens a partir dos quais se desenvolve uma narrativa que aborda, de forma rica e intensa, os temas aqui tratados. Para o acompanhamento deste filme foram gerados encontros e debates para observação da realidade apresentada no enredo, em comparação a outras informações deste grupo étnico africano. Assim, este trabalho se propõe a apresentar, de forma analítica, a utilização do filme como ferramenta de aprendizagem na sala de aula e instrumento facilitador e gerador de diálogos na formação escolar.
\end{abstract}

PalaVRas-ChaVe: Educação - África - Etnia - Cultura.

\begin{abstract}
:
Cultural differences, gender issues and the knowledge of the Samburu people in their relations with the geographical and social environment, issues addressed are discussed in this article, are constructed from based on the interaction between students and professors teachers from different disciplines subjects of the Colégio de Aplicação of the Federal University of Pernambuco, in Brazil. The guiding principle is the film The White Massai, based on a true story that shows the relationship of contrasts between a Swiss woman and a Samburu warrior, characters that help develop what is intended to be shown in this work. Debates and meetings were developed to observe the reality presented in the plot, compared to other pieces of information of this same African ethnic group. This work intends to present in an analyze, the film as a learning tool, a facilitator and generator of dialogues in education.
\end{abstract}

KEYWORDS: Education - Africa - Ethnicity - Culture.

\footnotetext{
${ }^{1}$ Doutor em Ciência Política pela UFPE e Docente do Colégio de Aplicação da UFPE. E-mail: erinaldocarmo@gmail.com

${ }^{2}$ Docente do Colégio de Aplicação da Universidade Federal de Pernambuco. E-mail: ericapatricia.bo@bol.com.br

${ }^{3}$ Especialista em Psicopedagogia. Pedagoga do Colégio de Aplicação da UFPE. E-mail: fernandamaria@oi.com.br
} 


\section{INTRODUÇÃO}

O filme $A$ Massai Branca, baseado na autobiografia de Corinne Hofmann (HOFMANN, 2011), a partir da narrativa do relacionamento entre uma mulher branca europeia e um homem negro africano, levanta uma interessante discussão sobre as diferenças culturais, incluindo as de gênero, ao expor o choque cultural vivido por ela ao se apaixonar e casar com um guerreiro Samburu, habitante de Barsaloi, uma comunidade afastada, onde não há eletricidade, água encanada, asfalto, posto médico, nem mesmo moradias confortáveis: os Samburus moram em cabanas adaptáveis a sua natureza seminômade.

A vida nessas condições é extremamente difícil aos nativos. Aos não-nativos é praticamente impossível. Por isso, o filme registra a superação de uma jovem capaz de abrir mão de toda comodidade que a cidade oferece para viver um amor desconhecido em um grupo social extremamente diferente da sua formação cultural europeizada. Inserida em um ambiente inóspito, completamente estranho aos costumes das sociedades urbanas modernas, ela presencia situações que lhe causam repulsa ou aceitação, consternação ou respeito, representando a assimilação da cultura local, ora com acomodação, ora com estranhamento do fato.

Entre os Samburus, grupo social fechado e de pouca referência externa, os interesses das mulheres não são considerados e estas são menos importantes que as cabras e as vacas, tendo em vista tratar-se de uma sociedade de pastores onde esses animais são essenciais à sobrevivência do grupo. Com uma formação machista, os Samburus praticam a mutilação genital das meninas ao entrarem na adolescência como uma forma de controlar a vida sexual femi- nina, não utilizam técnicas ou ferramentas de ampliação da produtividade e cultuam ritos que afastam homens e mulheres de uma convivência mais afetiva. Neste cenário perdido no tempo e no espaço, longe de tudo e de todos, a narradora se percebe ao longo de todo o enredo como um ser estranho. Apenas a malária a trata como igual.

\section{SAMBURU: História e TRADIÇÃo}

Como bem sabem os africanistas, ${ }^{4}$ uma etnia, na maioria das vezes, ocupa vários países, pois as fronteiras foram desenhadas segundo os interesses ocidentais e não seguindo a divisão étnica do continente africano (HUGON, 2009). Entretanto, a etnia Samburu, que vamos discutir ao longo do trabalho, localiza-se no Quênia, faz parte dos pequenos grupos étnicos que compõem $19 \%$ das etnias minoritárias deste país. Os que se destacam numericamente são os Quicuios, Luias, Luos, Calenjins e Cambas (FAVARO, 2008).

Os Samburus descendem dos mesmos ancestrais dos Massais, sendo confundidos com estes facilmente, como ocorre no filme A Massai Branca. Não há dúvida de que a linguagem é similar, derivado do "Maa", e os costumes são praticamente idênticos, mas é preciso assinalar uma característica peculiar dos Samburus: os seus guerreiros trazem argolas de marfim nas orelhas. Ainda é uma incógnita para os historiadores como a linhagem se separou. Os anciãos asseguram que os Samburus são originários de Núbia-Kush (região do Médio Vale do Rio Nilo), atual região sul do Sudão e se estabeleceram ao norte do Monte Quênia e ao sul do Lago Turkana na área do Vale do Rift

\footnotetext{
${ }^{4}$ Estudioso de qualquer nacionalidade e de qualquer saber acadêmico que tenha como foco a África e/ou suas relações com outros espaços do mundo.
} 


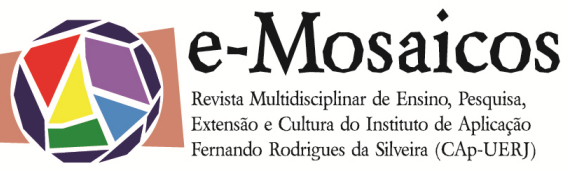

Africano $^{5}$ (Fig. 1) desde o século XV. Caracterizam-se por uma existência de seminomadismo e a sua economia está baseada no pastoreio de cabras e vacas. Como na maioria dos povos pastores africanos, a carne é pouco consumida: só em cerimônias especiais, como enterros, ritos, festas da circuncisão, casamentos, dentre outras. A dieta alimentar desta etnia está baseada no leite e, às vezes, no sangue das vacas, refletindo a dependência deste tipo de criação. $O$ sangue é coletado através de uma pequena abertura na jugular do animal. Após drenar o sangue necessário, a ferida é rapidamente selada com cinzas quentes. A dieta Samburu é complementada com raízes, legumes e tubérculos (CORTÉS; SALVADOR; ARNAU, 2006).
FIGURA 2 - Local de habitação dos Samburus, entre o Lago Turkana e o Monte Quênia

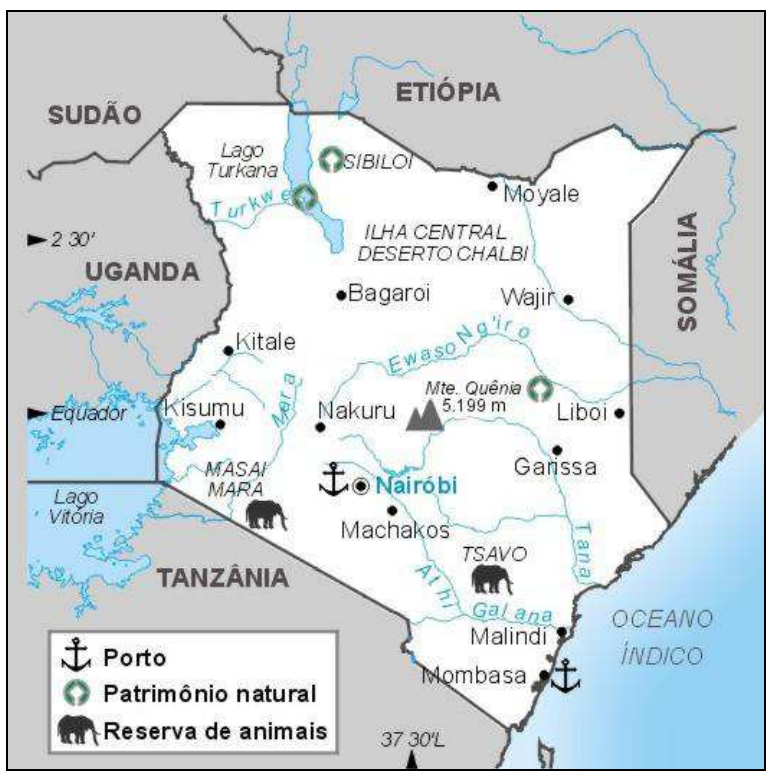

Fonte: Githiru; Ferraz, 2004.

A província do Rift Valley, no Quênia, é caracterizada por uma terra árida e semiárida, sendo necessário que esta etnia desloque-se periodicamente para assegurar alimento fresco aos animais. Suas cabanas são construídas de barro, couro e tapetes de grama. Uma cerca espinhosa é construída em torno das cabanas para a proteção contra os ataques de animais selvagens. Os barracos são construídos de modo que são facilmente desmontados, quando ocorre o movimento do grupo para um novo local. Esse povo geralmente vive em grupo de cinco a dez famílias. Os homens cuidam do gado e também são responsáveis pela segurança da comunidade. Os guerreiros defendem a etnia do ataque de homens de outros grupos e de animais selvagens. Eles também procuram invadir as terras de clãs rivais para roubar o gado (CORTÉs; SALVADOR, 2006).

Os meninos aprendem a cuidar do gado desde a mais tenra idade e também são 
ensinados a caçar. As meninas geralmente ajudam as mães com seus afazeres domésticos. Tanto as meninas como os meninos passam pela circuncisão, numa cerimônia de iniciação que marca a entrada na vida adulta (KENYA INFORMATION GUIDE, 2011).

Segundo Hugon (2009, p.43), "o papel da mulher é evidentemente central na criação cultural e seu status difere segundo a cultura". As mulheres Samburus são responsáveis pela coleta de raízes, legumes e água, além do cuidado das crianças e da manutenção da casa. A lista de atividades da mulher desta etnia inclui, ainda: a construção da casa e a realização de longas caminhadas para conseguir os materiais necessários; a permanente manutenção da casa no período mais úmido, utilizando material argiloso molhado misturado com esterco de vaca; a ordenha das vacas; o monitoramento dos animais doentes; a preparação da comida para todas as moradoras da casa (os homens não comem nada que uma muIher tenha preparado, apenas tomam o chá pela manhã e à noite); a coleta diária de água, lenha, raízes e ervas utilizadas para tratamento de doentes; a certificação de que o fogo não se apagou, para a preparação de alimentos e para o aquecimento da casa; a lavagem de roupas; a confecção de arte decorativa para ela, o marido e os fiIhos, além de outras atividades afins (THE AFRICA GUIDE, 2011).

Outra marca dessa linhagem é ser um grupo étnico falocrático e patrilinear, isto é, baseado nos ditames da figura masculina. A poligamia e a gerontocracia também caracteriza esse grupo, sendo permitido ao homem casar-se com quantas mulheres puder sustentar e aos anciãos gerenciar a estrutura social (FRANCO, 2007). Todos esses aspectos são passíveis de identificação no filme $A$ Massai Branca. Entretanto, de uma forma geral, os povos africanos têm, na ampliação do sistema de linhagem, a repre- sentação do poder, ou seja, pessoa é riqueza. Inclusive essa foi uma das muitas dificuldades de compreensão dos povos europeus em relação aos africanos da área Subsaariana, quando se depararam com os grupos étnicos menos complexos do ponto de vista da organização social. Para os europeus, a propriedade privada da terra é sinônimo de riqueza (OLIVEIRA; BARROS, 2011).

Conforme os costumes dos Samburus do Quênia, as meninas são iniciadas no ritual de passagem, onde ocorre a retirada do clitóris, na preparação para o casamento, geralmente com homens bem mais velhos, nos moldes tradicionais das suas antepassadas. A vida das mulheres Samburus, de acordo com a tradição, deve ser integralmente submissa ao pai e ao esposo (PASSOS, 2011).

Muitas consequências do processo de colonização vêm trazendo alterações definitivas nos padrões culturais deste grupo étnico. Um exemplo dessas transformações foram os ataques de soldados ingleses sediados no Quênia, nas proximidades onde vivem os Samburus. Eles realizavam exercícios militares nas décadas de 1980 e 1990. Mais de 50 mulheres foram estupradas pelos soldados enquanto recolhiam lenha. Apesar dos protestos e reivindicações dessas mulheres, que tinham como base o argumento de que foram violentadas pela ineficácia da proteção dos homens, responsáveis tradicionalmente por conferir a proteção das aldeias e das áreas de onde retiram a sobrevivência, as mulheres foram ridicularizadas, espancadas e obrigadas a abandonar o grupo étnico (PASSOS, 2011).

Inúmeras mulheres, vítimas do machismo e das injustiças do seu grupo, fundaram uma vila que se tornou símbolo de abrigo contra o casamento forçado, a mutilação genital feminina e o desprezo após os 
estupros. Estas vivem das atividades tradicionais, mas também da atividade turística agregada à venda de artesanato Samburu (PASSOS, 2011).

Tal como ocorre com muitas outras etnias da África Subsaariana, os Samburus estão sob forte pressão do governo queniano para se instalarem em povoados permanentes (SAMBURU COUNTY COUNCIL, 2011). Eles têm resistido ao estabelecimento permanente na terra, pois isto, obviamente, alteraria todo o seu modo de vida. As características naturais da área em que vivem dificultam o cultivo, pois são áreas áridas e semiáridas. Isto significa que a etnia iria ficar dependente de ações governamentais para complementação de sua renda. Uma vez que o status de riqueza da cultura Samburu está atrelado à quantidade de gado que possui, uma vida sedentária agrícola destruiria a estrutura social em que este grupo está assentado. Alguns integrantes deste clã foram forçados a resolver a problemática enviando os homens adultos para as cidades para trabalhar como guardas. Este é um tipo de trabalho que evoluiu naturalmente por causa da forte reputação dos Samburus como guerreiros natos (ABOUT AFRICA, 2011).

\section{NARRATIVA do filme: CONHECENDO OS DOIS MUNDOS}

O filme $A$ Massai Branca (The White Masal), uma produção alemã de 2005, dirigida por Hermine Huntgeburth, conta a história de uma turista suíça em visita ao Quênia, onde conhece um guerreiro Samburu. Uma atração inicial, mostrada pela cumplicidade na troca de olhares, aproxima o casal e dá início ao relacionamento tratado na filmagem. Carola é a protagonista desta história. Ela tem o seu primeiro contato com o negro africano, Lemalian, ainda na balsa, quando os olhares se cruzam - seus nomes verdadeiros são Corinne e Lketinga Carola e Lemalian são nomes fictícios criados para a realização do filme (HOFFMANN, 2007). Na sequência, no mercado de Mombasa, Lemalian impede um assalto em andamento que vitimizaria Carola e o seu então namorado, Stefan.

A primeira decisão alcantilada de Carola foi a de não voltar para a Suíça, mas permanecer no Quênia à procura de Lemalian. A determinação de ficar na África representa, para ela, um ato de coragem, não apenas por largar o seu mundo seguro, do trabalho, da família, do namorado, mas também por não temer os contrastes ao romper com o seu universo social para desbravar um mundo então incógnito. Ela própria se reconhece como uma pessoa que precisa de ordem, de uma visão clara das coisas. Entretanto, os odores, as cores, a mistura das pessoas, tudo isso lhe é estranho naquele lugar. Mesmo assim, o local lhe passa uma curiosa sensação de calma.

Desafiadora, Carola se engendra por áreas estranhas e hostis do Quênia que em nada reproduzem o seu cotidiano na Europa. Nas ruas de Mombasa ela procura por informações que a levem a Lemalian. Em seguida, já em Maralal, importante região das várias comunidades Samburu, encontra Elizabeth, uma mulher branca, também europeia e casada com um queniano, que a ajuda a percorrer a área comercial com uma foto do guerreiro tentando localizá-lo. Tarefa que não logrou êxito.

Depois de dez dias de cansativa espera, finalmente Lemalian surge, de pé na cerca da casa de Elizabeth, como um pastor que veio buscar o seu animal ou uma encomenda qualquer. Carola o segue sem nenhum questionamento e em um quarto simples o casal se relaciona intimamente, finalizados com o gozo masculino e o trauma feminino da relação sexual fria e sem pra- 
zer, do coito anal forçado, realizado apenas para a satisfação do guerreiro. Embaraçada, Carola deixa o quarto e Lemalian a procura interrogando-a com plena naturalidade se está tudo bem com ela. Carola responde que sim e então é chamada a ficar com ele. Ambos seguem para Barsaloi, povoado do seu grupo étnico.

Os dois experimentam a troca cultural. Apesar da narrativa ter sido produzida a partir do olhar feminino e europeu, é visível no filme o esforço de Lemalian para se aproximar dos padrões vividos por ela, principalmente quando estão fora dos olhares do grupo, inclusive com o rompimento de algumas tradições, como mostram as cenas em que fazem a refeição juntos, algo impraticável entre homens e mulheres Samburu, e quando ele se veste com roupas ocidentais para poder entrar no prédio de registro de imigração, e até mesmo quando praticam sexo com demonstrações de afetividade e carinho.

As cenas que apresentam as relações comerciais na loja de Carola também registram a dificuldade de Lemalian e dos Samburu em lidar com as regras do comércio. 0 dinheiro não tem a mesma importância para eles e as relações parentais e de amizade falam mais alto que as relações econômicas que regulam a necessidade do produto e 0 valor de mercado.

Ainda que trate da realidade de uma sociedade afastada, de pouco contato com a vida e os costumes urbanos, o filme registra a presença do Estado nesta localidade através da figura do subchefe, espécie de delegado da região, que intima Carola a ir embora ou se registrar para poder continuar ali, por ser proibida a moradia de pessoas brancas na aldeia. Em outro momento do filme, mostra-se a organização do poder na comunidade, através do julgamento promovido pelos homens mais velhos do grupo, uma espécie de conselho dos anciãos, com a presença de Carola, como parte envolvida no fato julgado, do padre como tradutor, e também de Lemalian, um pouco mais afastado e contemplativo. Nesta cena, o conseIho decide que Carola deve indenizar o subchefe com duas cabras por ter demitido o seu sobrinho da loja. Ao mesmo tempo, o subchefe é condenado a pagar cinco cabras pela agressão praticada pelo seu sobrinho contra Carola.

O contato amistoso de Carola com os clientes de sua loja, incluindo o sorriso e o olhar nos olhos, aguça o "ciúme" do seu marido. Alguns homens são acusados pelo humilhado guerreiro de terem relacionamento com Carola. Acusada de traição, ela leva um tapa no rosto e revida instantaneamente batendo no guerreiro diante de homens, mulheres e crianças que presenciavam a contenda. Diminuído diante de sua comunidade, Lemalian tira o traje típico de guerreiro e corta os cabelos. Este acontecimento é acompanhado de ameaças a Carola e de agressão ao padre dentro da loja.

A inviabilidade de continuarem vivendo juntos leva Carola a providenciar sua volta para a Suíça, levando a filha sob o argumento de que a criança iria conhecer a avó materna. Receoso em assinar a autorização para o embarque da filha, Lemalian questiona insistentemente se Carola pretende voltar. No instante da partida ele afirma saber que ela não voltará. Assim se dá o encerramento de uma história de coragem e troca entre duas culturas tão afastadas, representadas por duas vidas tão próximas.

\section{Cinema e Práticas discursivas}

Com a abordagem de conteúdos culturais que permitem a compreensão dos fatos, a comparação entre diferentes grupos e a narrativa contextualizada, o filme $A$ Massai Branca permite uma linguagem em ação 
que pode ser facilmente utilizada como prática discursiva em sala de aula. Por meio dessa linguagem, o filme produz sentidos sobre a distinção de gêneros, de culturas e de papéis, numa narrativa construída, enquanto prática cultural e discursiva, que possibilita uma multiplicidade de representações e percepções sobre o mundo e sobre as ações dos sujeitos envolvidos.

Sua personagem central está inserida em um novo contexto, contemplando situações adversas aos seus hábitos e que lhe cobram respostas imediatas e ao mesmo tempo adequadas ao seu novo grupo de convívio. A assimilação de uma nova cultura não é um processo rápido e simples, por isso os frequentes estranhamentos de Carola. Neste caso, o estranhamento significa um espanto diante de algo que não se conhece. Por achar estranho ou sentir-se incomodado diante do novo, ou por não se conformar com a realidade presenciada, o sujeito é incentivado a não se acomodar. Aqui, o estranhamento, num primeiro momento, suscita a rejeição, quando o sentido de estranhar o que não é normal, ou comum, significa não se conformar, mas buscar uma postura de resistência. Por outro lado, este estranhamento produz uma sensação de incômodo e a necessidade de encontrar mais informações que orientem na compreensão do diferente, no entendimento daquela realidade, sendo assim uma forma de ir além das primeiras impressões e das primeiras respostas balizadas pelo senso comum.

A assimilação representa um ajustamento interno do próprio sujeito em adequação a uma nova realidade. Trata-se de um processo social de integração do indivíduo a um grupo diferente, onde o sujeito adquire e acolhe os padrões comportamentais e as tradições coletivamente aceitas. Daí o esforço de Carola em se adaptar a certas regras do seu novo grupo social, mesmo contrariando sua formação europeia. Ao mesmo tempo em que se registra na narrativa uma mulher independente, corajosa e reguladora de suas próprias decisões, também se assiste ao ideário romântico de uma jovem que se submete às regras grupais e ao controle machista do seu marido. A decisão de ficar no Quênia, seguir o Samburu, comprar um carro e abrir uma loja em Barsaloi, está diretamente associada ao romantismo sonhado de Carola. Neste sentido, as decisões observadas como possíveis práticas de autonomia do sujeito, como medidas estritamente racionais, não descartam o âmbito emocional, nem desprezam o sentido coletivo, mesmo das ações individuais. Carola, assim com Elizabeth, personagens femininas de destaque no filme, são mulheres que abandonaram família, amigos e estilos de vida na busca do homem dos sonhos, do ideal amor romântico e, ainda que fortes, precisam se mostrar subservientes diante do marido e deste novo modo de vida voluntariamente adotado.

Mesmo quando contesta a mutilação genital, a partir dos valores culturais de sua formação primária, Carola percebe a limitação de sua oposição a uma regra tradicionalmente estabelecida e aceita pelo grupo. Na cena, o padre também reconhece a prática como abominável, mas reitera a necessidade de não contestar os costumes locais, o que mostra a dificuldade dos agentes externos em se desvencilhar dos ritos de sua cultura de formação para aceitar os ritos de outras. Sobre esta temática, há uma outra concepção sobre a mutilação genital feminina que é defendida pelos relativistas culturais. Para esses, as influências ocidentais que interferem nessa prática são intervenções etnocêntricas que reprimem as culturas africanas. Os relativistas culturais argumentam que os discursos sobre os direitos humanos universais negam a soberania cultural dos povos menos poderosos, comprome- 
tendo a tolerância e o multiculturalismo, e promovem atitudes racistas (BRYM, 2006).

Também chocam as imagens da muIher grávida caída ao chão em trabalho de parto, sendo observada por pessoas que se recusam a ajudá-la. Em seu socorro, Carola pede auxílio a Lemalian, que após relutar a atende, mesmo justificando que aquela muIher não poderia ser tocada por estar enfeitiçada. O choque ocorre por revelar regras que são naturalmente aceitas naquele grupo, mas se colidem com as regras culturais difundidas nas demais sociedades. É que cada sistema cultural tem sua própria lógica e tentar transferir a lógica de um sistema para outro não passa de um ato primário de etnocentrismo. Há uma prática comum nas sociedades industrializadas em considerar lógico apenas o seu próprio sistema cultural, enquanto se atribui aos demais um alto grau de irracionalismo (LARAIA, 2003). Para Lemalian, tocar aquela mulher enfeitiçada e se contaminar representa um esforço tão grande quanto o praticado por Carola ao renunciar a suas origens para viver naquele ambiente.

De uma forma geral, a narrativa do filme provoca o sentimento de assimilação ou estranhamento dos ritos diferentes e exóticos, estimulando práticas discursivas sobre os temas nele abordados. Possibilita, ainda, a reflexão sobre diferentes formações culturais e permite o conhecimento, ainda que superficial, dos costumes de um grupo tipicamente africano, de uma cultura de resistência na preservação do seu estado original, quase sem hibridismo, de baixo envolvimento com a cultura ocidental e sem reflexo do consumismo do modelo globalizado.

\section{CONSIDERAÇõEs FinaIS}

A utilização do filme como recurso didático possibilita a aprendizagem de forma mais atrativa e dinâmica, permitindo uma assimilação de conteúdos abstratos de forma mais concreta, o que resulta numa aprendizagem não apenas dos conteúdos relacionados aos objetivos estabelecidos, como também motiva o aluno à pesquisa, 0 que resulta no desenvolvimento de uma postura autônoma e reflexiva. O filme $A$ Massai Branca foi escolhido como instrumento para o desenvolvimento desta estratégia didático-pedagógica pelo que se expõe a seguir: a) possibilitar a identificação do multiculturalismo e a discussão sobre o etnocentrismo; b) permitir o debate sobre a questão de gênero, com atenção especial ao papel secundário da mulher nesta cultura; c) registrar o distanciamento da produção rudimentar em relação ao modelo produtivo em larga escala das sociedades modernas; d) narrar a trajetória de convivência e resistência de uma comunidade tribal com sua cultura original ainda preservada; e) demonstrar as dificuldades de uma sociedade nômade em suas relações exógenas.

A partir do acompanhamento do filme A Massai Branca, baseado no best-seller de Corinne Hofmann, e dos diálogos proporcionados pelos seus principais personagens, foram abordadas em sala de aula, com estudantes do Ensino Médio, temáticas inerentes às disciplinas de Geografia e Sociologia, as quais foram trabalhadas nas aulas da Parte Diversificada de forma interdisciplinar.

A questão de gênero, como visualizada no filme, foi bastante debatida, considerando as devidas variações culturais, e comparada a outras realidades. Foi visto que entre os Samburus os papéis são bem definidos por gênero. Os homens cuidam do gado e os mais fortes também são guerreiros que defendem a comunidade de ataques de outros grupos e de animais selvagens. Estes guerreiros também são responsáveis pela invasão de outras terras dos clãs rivais. A educação foi entendida como um fator de 
manutenção dessa tradição, visto que desde menino, os homens aprendem a pastorear e a caçar. Já as meninas aprendem as atividades domésticas, reforçando o papel da mulher, que é o mais sacrificante, pois esta tem atividades suficientes para ocupar todo o seu dia, tomando conta da casa, das crianças e dos animais, sempre em subserviência ao pai ou ao marido.

Ainda sobre a temática de gênero, os alunos discutiram como a cultura tradicional mantém as práticas de domínio masculino e submissão feminina, inclusive no costume Samburu de mutilação das meninas durante o ritual de passagem, onde ocorre a retirada do clitóris em preparação para o casamento, geralmente com homens bem mais velhos.

Sobre a cultura de resistência dos Samburus, os debates se pautaram na pressão do governo para fixação do grupo em um espaço definido. O entendimento comum foi de que esta medida alteraria todo o modo de vida desta tribo, visto que as características naturais da área em que vivem dificultam o cultivo e isto colocaria a etnia na dependência de ações assistencialistas do Estado para complementação de renda, o que retiraria a autonomia do grupo e eliminaria a tradicional utilidade dos guerreiros. Ainda em relação à cultura Samburu, foi reconhecida nos diálogos entre alunos a dificuldade deste povo em lidar com o valor do dinheiro, com o preço dos produtos e com as regras gerais do comércio. As relações parentais se sobrepõem às relações econômicas.

O mesmo estranhamento, registrado pela protagonista do filme, também esteve presente nos debates em sala de aula. De início, houve uma rejeição diante do desconhecimento da cultura diferente, uma ausência de resignação para as práticas não aceitas socialmente, como por exemplo, a circuncisão feminina. Esta sensação de in- cômodo levou os participantes a buscar mais informações sobre o tema para orientar seus argumentos além das primeiras impressões demarcadas pelo conhecimento do senso comum. Por isso, concluímos que esta prática pedagógica com a utilização do filme $A$ Massai Branca mostrou-se extremamente interessante por estimular o diálogo entre os alunos sobre temas relevantes, permitindo a manifestação de suas ideias durante os debates, promovendo a pesquisa sobre os assuntos abordados e favorecendo o empenho destes estudantes na continuação desses estudos e na seleção de temas correlatos.

\section{REFERÊNCIAS BIBLIOGRÁFICAS:}

ABOUT AFRICA. The Samburu of Kenya. The United States of America: Tribes of Africa. Disponível em: <http://goafrica.about.com/library/bl.sambu ru.htm>. Acesso em 31/01/2011.

BRYM, Robert. Et. al. Sociologia: sua bússola para um novo mundo. São Paulo: Thompson, 2006.

CORTÉS, José Luís; SALVADOR, Leo; ARNAU, Arturo. Os Samburu. Portugal: Revista Além-Mar, abril de 2006. Disponível em: <http://www.alem-mar.org/cgibin/quickregister/scripts/redirect.cgi?redirect $=$ EEuupZkkFVMurYmFDi>. Acesso em 04/02/2011.

FAVARO, Thomaz. Infeliz ano novo: o Quênia era um dos poucos países africanos que fugiam à maldição das rivalidades tribais. São Paulo: Revista Veja, 9 de janeiro de 2008. Disponível em: $<$ http://veja.abril.com.br/090108/p_050.sht $\mathrm{ml}>$. Acesso em 13/03/2011.

FRANCO, Edson. Até que a morte os separe: casamentos na África, Ásia e Oriente Médio mostram as regras que regem a união de um homem com uma mulher... ou 
mais. Rio de Janeiro: Revista Galileu, agosto de 2007. Disponível em: <http://revistagalileu.globo.com/Revista/Gal ileu/0,"EDG78246-8489-193,00.html>. Acesso em $22 / 01 / 2011$.

GITHIRU, Samwel Kamau; FERRAZ, Henrique. Quênia: entre tradições e a globalização. São Carlos/SP: Revista Eletrônica de Ciências, agosto de 2004. Disponível em: $<$ http://www.cdcc.usp.br/ciencia/artigos/art _27/africa.html>. Acesso 22/02/2011.

GUERRA, Antônio Teixeira. Dicionário geológico e geomorfológico. Rio de Janeiro: IBGE, 1993.

HOFFMANN, Corinne. A Massai branca: meu caso com um guerreiro africano. São Paulo: Geração Editorial, 2011.

HUNTGEBURTH, Hermine. A Massai branca (The White Masai, Die Weisse Massai). Alemanha, 2005. DVD, 132 min. cor. som.

HUGON, Philippe. Geopolítica da África. Rio de Janeiro: Editora FGV, 2009.

KENYA INFORMATION GUIDE. Samburu: a kin of the Maasais. Kenya: The Samburu Tribe of Kenia. Disponível: $<$ http://www.kenya-informationguide.com/samburu-tribe.html>. Acesso em 03/03/2011.

LARAIA, Roque. Cultura: um conceito antropológico. Rio de Janeiro: Jorge Zahar, 2003

OLIVEIRA, Érica Patrícia Barbosa de; BARROS, Natália. Estranhamentos: representações sobre gênero e etnia no filme $A$ Massai branca. In: VII Colóquio Nacional Representações de Gênero e de Sexualidade, de 17 a 16 de junho de 2011, Campina Grande, Paraíba. Anais... Campina Grande: Realize Editora, 2011. [CD-ROM]

PASSOS, Walter. UMOJA, Aldeia da Liberdade. Kenya: Bayah, 26 de abril de 2011. Disponível em: <http://cnncba.blogspot.com.br/2011_04_0

1_archive.html>. Acesso em 25/05/2011.

SAMBURU

COUNTY

COUNCIL.

Representing the Samburu people of northern Kenya. Kenya. Disponível em: $<$ http://www.samburucouncil.com/index.ht $m>$. Acesso em 25/02/2011.

THE AFRICA GUIDE. Tribes \& people groups: Samburu. The United States of America: African People \& Culture. Disponível

em:

$<$ http://www.africaguide.com/culture/tribes/ -samburu.htm>. Acesso em 22/03/2011. 